\title{
Young Children Understand the Role of Agreement in Establishing Arbitrary Norms-But Unanimity Is Key
}

\author{
Marco F. H. Schmidt \\ LMU Munich and Max Planck Institute for Evolutionary \\ Anthropology
}

\author{
Hannes Rakoczy \\ University of Göttingen
}

Teresa Mietzsch and Michael Tomasello

Max Planck Institute for Evolutionary Anthropology

\begin{abstract}
Human cultural groups value conformity to arbitrary norms (e.g., rituals, games) that are the result of collective "agreement." Ninety-six 3-year-olds had the opportunity to agree upon arbitrary norms with puppets. Results revealed that children normatively enforced these novel norms only on a deviator who had actually entered into the agreement (not on dissenting or ignorant individuals). Interestingly, any dissent during the norm-setting process (even if a majority of $90 \%$ preferred one course of action) prevented children from seeing a norm as established for anyone at all. These findings suggest that even young children understand something of the role of agreement in establishing mutually binding social norms, but that their notion of norm formation may be confined to conditions of unanimity.
\end{abstract}

Humans make binding agreements and thereby create enforceable social norms that structure their social interactions. For instance, a local group of people might agree upon dressing in a certain way or behaving in a certain way in public. And so, unlike natural facts that are discovered (e.g., clothes keep you warm), conventional norms are socially constructed practices that exist by "agreement" (e.g., clothes must be worn in public; Hart, 1961; Kelsen, 1960; Searle, 1995). Young children therefore face the developmental task not only of learning the conventional norms adults expect them to follow, but also of understanding the nature of conventional norms as agreements that can be created or destroyed by people at will (Kalish, 2005; Killen \& Rutland, 2011; Rakoczy \& Schmidt, 2013; Schmidt \& Tomasello, 2012; Turiel, 1983).

We are grateful to the research assistants at the Max Planck Institute for Evolutionary Anthropology, especially Eva Siegert, Jana Jurkat, Nadin Bobovnikov, and Rahel Döring for help in recruiting children, collecting data, and coding. We also thank three anonymous reviewers and Joanna Buryn-Weitzel for helpful comments on an earlier draft of this article, Roger Mundry for statistical advice, and all day-care centers, children, and parents for participating in our study. The first author was supported by a postdoctoral fellowship from the Max Planck Society.

Correspondence concerning this article should be addressed to Marco F. H. Schmidt, International Junior Research Group Developmental Origins of Human Normativity, LMU Munich, Leopoldstraße 13, 80802 Munich, Germany. Electronic mail may be sent to marco.schmidt@psy.lmu.de.
There are three prominent ways by which norms come into existence: (a) behavioral regularities, such as in coordination situations in which rationality and interdependence demand and guide personal success, may gain bindingness over time and thus become normative and self-enforcing (Lewis, 1969); (b) authorities, such as parents or the state, may create and enforce norms (Cummins, 2013; Piaget, 1932); or (c) participants of a social practice may set norms by agreement among equals (Gilbert, 2008; Piaget, 1932). The latter mode of norm creation is strikingly different from the first two regarding the source of the normative force: While the bindingness of coordination norms stems mainly from (selfinterested) rationality and the bindingness of otherset norms is often coercive and authority based, the bindingness of agreed-upon norms comes from their legitimacy for "us," as parties of the voluntary agreement (Piaget, 1932; Tuomela, 2007).

A wealth of studies mainly using interview techniques have revealed that school-aged (and to a lesser extent preschool) children make subtle distinctions between different types of existing norms, such as group-transcending moral norms (that pertain to issues of well-being or justice) ver-

(C) 2016 The Authors

Child Development (c) 2016 Society for Research in Child Development, Inc. All rights reserved. 0009-3920/2016/8702-0020

DOI: $10.1111 /$ cdev. 12510 
sus group-specific conventional norms (related to issues of social organization; Smetana, 2006; Turiel, 1983, 2006). With increasing age, children apply and reason about these norms very flexibly, balancing different concerns (e.g., group vs. moral ones) in intra- and intergroup contexts regarding a variety of issues like resource allocation, social exclusion, deviance, prejudice, or bullying (Abrams, Palmer, Rutland, Cameron, \& Van de Vyver, 2014; Abrams, Rutland, \& Cameron, 2003; Abrams, Rutland, Ferrell, \& Pelletier, 2008; Cooley \& Killen, 2015; Hitti, Mulvey, Rutland, Abrams, \& Killen, 2014; Killen \& Rutland, 2011; Mulvey, Hitti, Rutland, Abrams, \& Killen, 2014a, 2014b; Nesdale, Lawson, Durkin, \& Duffy, 2010; Nesdale et al., 2009; Rutland, Killen, \& Abrams, 2010). Hence, school-aged children understand much about the context relativity and ultimately social nature of many norms.

With respect to younger children, a set of recent studies using interactive methods has found that around age 3, children spontaneously criticize and protest third-party violations of norms that were set by authorities or were preexisting (e.g., Kenward, 2012; Rakoczy, Warneken, \& Tomasello, 2008; for reviews, see Rakoczy \& Schmidt, 2013; Schmidt \& Rakoczy, in press; Schmidt \& Tomasello, 2012). Consistent with social domain theory (Smetana, 2006; Turiel, 1983, 2006), these studies suggest that 3-year-olds conceptualize norms introduced by adults as context- and group-relative phenomena, unless moral issues are involved (Rakoczy, Brosche, Warneken, \& Tomasello, 2009; Schmidt, Rakoczy, \& Tomasello, 2012; Wyman, Rakoczy, \& Tomasello, 2009). And compared to 2 -year-olds, children at age 3 apply norms more impartially, for instance, in that they protest others' property violations irrespective of whether they are the victim or not (Rossano, Rakoczy, \& Tomasello, 2011). However, none of this work has looked at young children's understanding of the mechanisms of norm establishment. Older children (aged 5) can create their own norms for coordination in an instrumental task (i.e., such norms are self-enforcing based on rationality), but they criticize any deviants as if their norms were discovered objective facts rather than subjective and co-constructed (Göckeritz, Schmidt, \& Tomasello, 2014; see also Nobes, 1999). Thus, these studies leave open the questions of (a) whether young 3-year-old children would understand novel, jointly agreed-upon arbitrary norms (that neither solve coordination problems nor were preexisting or set by adults) as mutually binding and enforceable, and (b) under which conditions (e.g., unanimous agreement among norm creators vs. dissent) children understand novel norms as being in effect and to whom created norms apply. Answers to these questions would help shed light on the mechanisms of children's norm acquisition and enforcement (i.e., Do they merely adopt and enforce adults' precepts or also novel spontaneously agreedupon norms?), their construal of how norms - even arbitrary ones - can be established, and their motives for enforcing norms (e.g., commitment to an agreement might enhance motivation to defend it).

It is vital to distinguish between the four paradigmatic cases in which norms can be established by agreement (of course, any list of cases cannot be exhaustive, but rather comprises mainly prominent cases). First, there may be unanimous agreement among parties in a particular context to perform a social practice in a certain way, dub this Norm A. Hence, every party involved in the agreement has a normative standing to demand conformity to A from the other parties (Carassa \& Colombetti, 2014; Darwall, 2006; Gilbert, 2008). That is, $\mathrm{A}$ is binding, since all parties were part of the Norm-setting process, and all parties agreed (Kalish, 2005). Any nonconforming party is thus subject to criticism and all parties of the agreement are entitled to know and be informed about deviant parties who broke the agreement. Note that here we use the term unanimous agreement since the notion of "consensus" may be interpreted more loosely include cases of approximate unanimity or widespread agreement, but not necessarily unanimous agreement (McAdams, 1997; Prothro \& Grigg, 1960). Second, it may be that one party is ignorant of the group's agreement on A, for instance, due to absence during the norm-setting process. Here, the group has no normative standing to demand conformity to A from the ignorant party, since the person was not part of the norm-setting process, the person's explicit agreement is lacking (Gilbert, 2008), and the person cannot conform to A without knowing what A is (Kalish, 1998). Third, it may be that one party quits the norm-setting process and announces that he or she would perform an alternative Action B, while the group has agreed-upon Norm A. Then, the group has no normative standing to demand conformity to A from the quitting party, since the party's explicit agreement is lacking -and this freedom not to enter into the agreement is backed by the group's mutually cooperative and egalitarian relationship and the mutual respect for each party's autonomy and voluntary participation (Kalish, 2005; Nucci, 2014; Nucci \& Weber, 1995; Piaget, 1932). And fourth, the most intricate case 
may be dissent within the group: One party disagrees with the group's preference for A and tries to assert an alternative Norm B for the group (hence, the party does not leave the norm-setting process, but instead intends to participate in creating a norm). There are three major possibilities of how to deal with dissent: It could be that (a) the social scope is limited and Norm A applies only to those who agreed on it (i.e., to affirmers, but not to dissenters), (b) no norm gets established whatsoever as there is no unanimous agreement (e.g., due to egalitarian thinking, such that all parties are equivalent, have an equal say, and full agreement is required for norm formation - a practice common in hunter-gatherer societies; Boehm, 1999; Gray, 2009), or (c) the majority determines the course of action, so that Norm A is binding for everyone (both affirmers and dissenters).

Although prior work on 3-year-olds' understanding of the context and group relativity of social norms set by adults might be taken to militate for the first possibility, it does not directly speak to situations of norm formation under conditions of dissent, which are of interest here, because children in previous studies learned norms either without conflicting information or, if there was a conflict, the model's status (e.g., authority vs. peer) was manipulated (Rakoczy, Hamann, Warneken, \& Tomasello, 2010). Of more relevance is recent research on children's social learning strategies and epistemic trust, which suggests that young children might endorse the second option (no norm establishment). For instance, when facing a forced-choice discrimination task in which children can revise their initial individual decision, 3- to 4-year-olds are solely influenced by a group of informants that agree unanimously and not by nonunanimous informants such as a majority of $90 \%$ (Morgan, Laland, \& Harris, 2015). Furthermore, 3-year-old children prefer to copy an action performed uniformly by a majority rather than a different act performed by a minority (Turner, Nielsen, \& Collier-Baker, 2014), they mistrust informants that are not $100 \%$ correct in labeling familiar objects (Pasquini, Corriveau, Koenig, \& Harris, 2007), and they tend to learn novel object labels and functions more from informants that are in full agreement with each other than from a lone dissenter (Corriveau, Fusaro, \& Harris, 2009; Seston Schillaci \& Kelemen, 2013). Moreover, young children also modulate their public judgments (i.e., they conform despite knowing better) in the face of peers or adults that make unanimous judgments (Corriveau \& Harris, 2010; Haun \& Tomasello, 2011). A second strand of research on children's evaluation of decision-making procedures provides further support for the idea that young children might favor unanimous agreement over majority rule: It is not until about 9 years that children prefer majority rule regarding political decisions, and interestingly, young school-aged children endorse full agreement (rather than majority rule) in peer groups and family environments that are less hierarchical in structure than, for example, school contexts (Helwig, 1998; Helwig \& Kim, 1999). Finally, research based on the developmental subjective group dynamics model suggests that it is not before around 8 years of age that children pay particular attention to loyalty and normatively aligned behavior in their own group, disfavoring in-group deviants (Abrams et al., 2003, Abrams et al., 2014; Rutland et al., 2010). That is, younger children might be less prone to negatively evaluate a dissenter within their group (Cooley \& Killen, 2015), to perceive dissent as threatening group cohesion, or to expect the majority to establish in-group norms (as opposed to focusing on unanimity).

Taken together, the reviewed research suggests that young children at age 3 understand aspects of normativity (i.e., context and group relativity) essential to the conception that norms are social phenomena that can be set by agreement. On the other hand, 3-year-olds are somewhat rigid in their evaluation and use of social information in that they preferably learn and base their own acts on others' uniform and unanimous behavior.

In two experiments, therefore, we first investigated whether 3-year-old children would enforce jointly agreed-upon arbitrary norms against a deviating party, contrasting the four paradigmatic cases in four conditions (agree, disagree, ignorant, quit). However, given the three major options (limited social scope, no norm establishment, majority rule) of how one can deal with dissent during the normsetting process and the resulting question of whether children need unanimous agreement to see norms as established at all, we conducted a second experiment. Here, 3-year-olds witnessed a lone dissenter against an overwhelming majority $(90 \%$ including the child) during the norm-setting process and then a deviating party that was either a previous affirmer or the previous dissenter regarding the suggested norm.

Importantly, in our experiments, there was neither a need for children to work together to achieve a goal (hence no coordination problem) nor an authority figure teaching children some preexisting norms. Rather, in a structured context, children had the opportunity to jointly agree upon highly arbi- 
trary norms (akin to, e.g., games, dress norms, or rituals) with hand puppets, and to enforce those novel norms against nonconforming parties. We chose arbitrary, and seemingly functionally opaque, norms because they are exemplary for human-made institutional reality and cultural life (Legare \& Souza, 2012; Nielsen, Kapitány, \& Elkins, 2015), and particularly interesting given that their normativity cannot be reduced to things like coercive power of authority or the self-enforcing nature of solutions to coordination problems. Rather, normative expectations about arbitrary practices in a situation of prima facie independence (i.e., each party could also perform her own idiosyncratic action) suggest some appreciation of the social nature of normative force (Rossano, 2012; Schmidt \& Tomasello, 2012; Tomasello, 2009).

Based on the notion that 3-year-olds' understanding and enforcement of social norms is underlain by their developing identification with their cultural group (Schmidt \& Tomasello, 2012) and based on prior research (i.e., 3-year-olds' contextand group-relative understanding of social norms but also their focus on unanimity), we predicted that children would normatively enforce jointly agreed-upon norms only when the deviator had entered into the agreement, but not when the deviator had disagreed with the suggested norm, had been ignorant of the norm, or had quit the normsetting process. Moreover, we hypothesized that children's own spontaneous level of agreement with suggested norms would be predictive of their norm enforcement. Regarding Experiment 2 (in which there was no unanimity), if children need unanimous agreement to understand norms as being in effect, they should not protest against any deviator. Alternatively, children should protest violations of a previous affirmer, but not of a previous dissenter, if they understand the social scope of agreed-upon norms as limited to those who agree. Finally, if even a large majority of $90 \%$ would not lead children to infer that norms have been established for all, this would suggest that young children do not consider majority rule as a procedure for norm formation.

\section{Experiment 1}

\section{Method}

\section{Participants}

Sixty-four 3-year-old children $(M=42$ months, range $=40-44$ months; 32 girls, 32 boys) partici- pated in the study. Children were native German speakers, came from mixed socioeconomic backgrounds from Leipzig, Germany, and were recruited from June to November 2012 via urban day-care centers (in which testing took place). Parents provided written informed consent. One additional child was tested but excluded from the final sample due to experimenter error.

\section{Design}

After a warm-up session, children received four trials of norm-setting tasks (the order of tasks was systematically varied). Children were randomly assigned to one of four between-participants conditions: agree, disagree, ignorant, or quit.

\section{Materials}

In each norm-setting task, an object with two symmetrically arranged locations and a small stuffed animal were used (see Figure 1 and Appendix S1).

\section{Procedure}

Two experimenters conducted the study: E1 who operated two puppets (Affirmer 1, Affirmer 2), and E2 who operated two puppets (proposer, protagonist). The child, E1, and E2 sat at a table (Figure 1). In the warm-up session, children and the four puppets played with a ball and a puzzle, and in an instrumental task, children had the opportunity to correct the protagonist who made a mistake (putting a disk vertically onto a peg, so it would not fit).

Table 1 provides a detailed overview of the four conditions and the phases of the norm-setting task

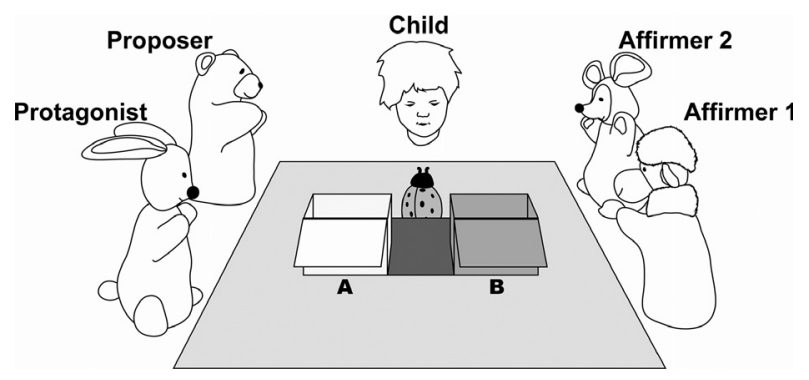

Figure 1. Experimental setup (Experiment 1). Children sat at a table with four puppets. In each norm-setting task, a small stuffed animal and an object with two alternative, differentcolored locations A and B were placed on the table (e.g., a ladybug and a platform with two boxes). 
Table 1

Experiment 1: Phases and Measures in the Norm-Setting Task for Each Condition

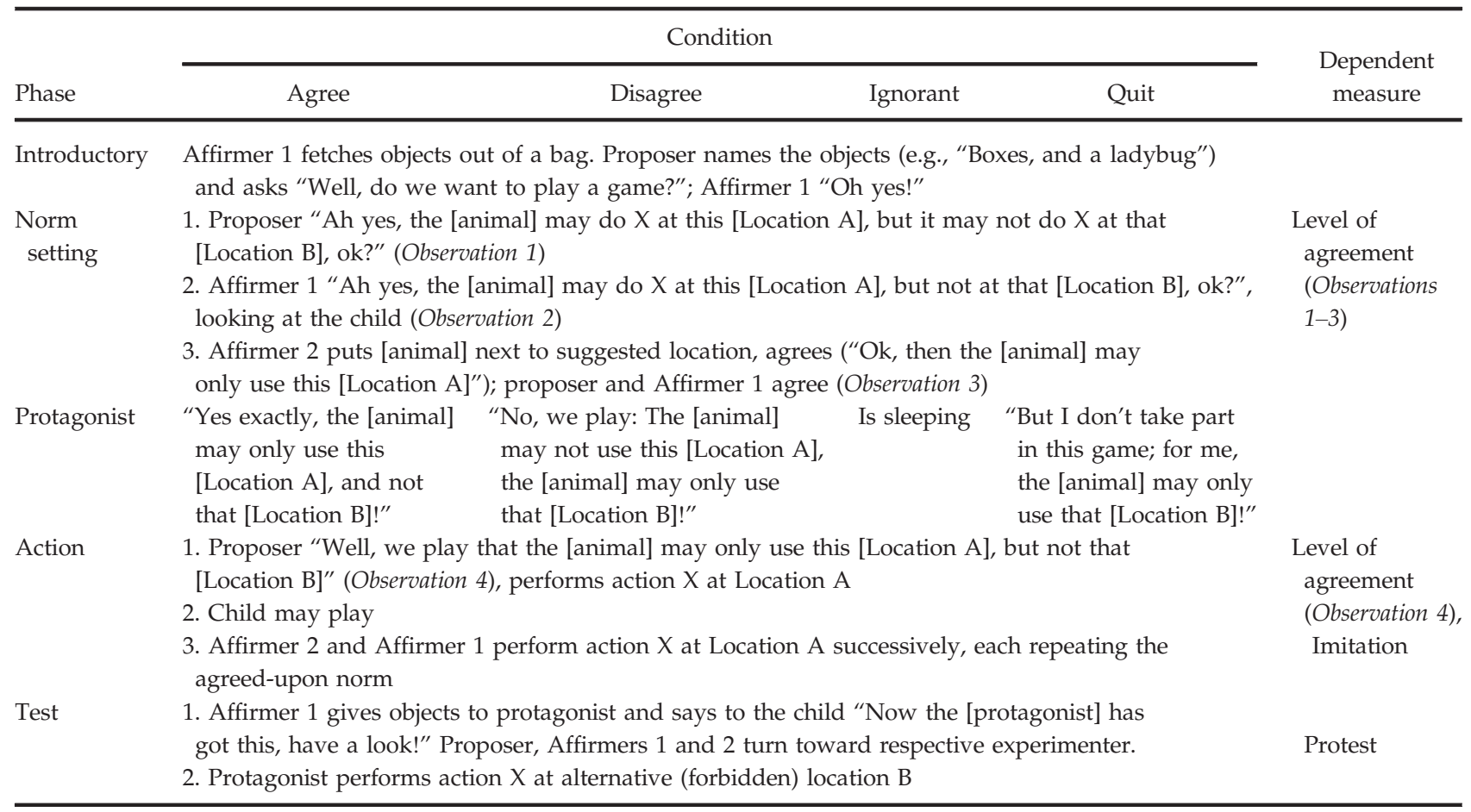

Note. In the norm-setting phase, Affirmer 1 repeated her question (Observation 2) if a child explicitly disagreed with the proposal (see Coding section for more information). To establish an authentic context in which there is a reason to agree upon novel game norms, Affirmer 1 stated, before the first trial, that she received a bag with objects without knowing its contents. In the ignorant condition, the protagonist "went to sleep" before the introductory phase, came back after the action phase (saying "I'm back"), and was welcomed by Affirmer 1, "Ah, the rabbit is back again and doesn't sleep anymore." The status of location (permitted, forbidden) was counterbalanced across children. $\mathrm{X}=$ action performed (see Appendix S1) with stuffed animal at Location A/B.

including the dependent measures recorded. In each norm-setting task the proposer suggested playing a game whose structure was that a stuffed animal was allowed to perform an action $X$ at one location (A), but not at the other location (B). In one task, for instance, the proposal was that a ladybug may sleep in one box (A), but that it may not sleep in the other box (B; see Appendix S1 for materials and actions used in the norm-setting tasks). During the test phase, the protagonist performed the action $\mathrm{X}$ at the forbidden Location $\mathrm{B}$, and children's spontaneous protest responses were measured while the other three puppets were facing away from the table toward the respective experimenter (i.e., the other parties were still present and addressable, but not witnessing the protagonist's act).

\section{Coding and Dependent Measures}

All sessions were recorded, transcribed, and coded from videotape by a single observer. A second independent observer, blind to the hypotheses and conditions of the study, transcribed and coded a random sample of $20 \%$ of all sessions for reliability.

Level of agreement. Children's spontaneous level of agreement with the suggested norm was coded via four observations (before children's own actions on the objects to obtain an unbiased measure of their agreement; see Table 1). For each observation, children received a score ranging from -2 to +2 :

1. -2 , explicit disagreement (e.g., "No, the other [location]!"); utterances and gestures like "No" or head shaking in response to the puppets' negative phrases (e.g., ". . . the [animal] may not play at that location [B]"), were not coded, because they could either be understood as agreement (e.g., "No, it may not ...") or as disagreement (e.g., "No, it may . ..");

2. -1 , implicit disagreement (e.g., pointing to the forbidden location $\mathrm{B}$, and other implicit forms of disagreement, such as "Why?" and "And the other [location]?");

3. 0 , no reaction; 
4. +1, implicit agreement (e.g., nodding, affirmative interjection "Mm-hmm");

5. +2, explicit agreement (e.g., "Yes!" "OK!" and "Alright!" repeating the prohibition "Not into that [location]!").

If a child scored on levels of only one polarity (agreement: +1 and +2 ; disagreement: -1 and -2 ) within one observation, the highest score was given (e.g., +2 or -2 ). If a child scored on levels of both polarities (e.g., $-1,+1$, and +2 ), the highest scores of each polarity were summed (e.g., $-1+2=+1$ ). The rationale here is to reflect a child's indecision (e.g., both agreement and disagreement within one observation) by summing up the highest scores of each polarity. This approach thus takes into account inconsistent and consistent behaviors for each observation. For each child, the level of agreement per trial was computed by summing up the four individual scores obtained for each observation (yielding a range of the summed score per trial of -8 to +8$)$. A (continuous) mean score $(-8$ to +8$)$ of level of agreement over the four trials was computed for each child by summing up the agreement scores of each trial and dividing the resulting sum by the total number of trials.

Imitation. Children's imitation (i.e., choosing the suggested Location A vs. the prohibited Location B during the action phase) was assigned one of the following mutually exclusive codes including a score ranging from -1 to +3 : (a) exclusive imitation, +3 (Location A only); (b) inclusive imitation, +2 (first $\mathrm{A}$, then B); (c) weak inclusive imitation, +1 (first B, then A); (d) no imitation, 0; or (e) deviation, -1 (Location B only). Each child received a (continuous) mean score $(-1$ to +3$)$ of imitation by summing up the imitation scores of each trial and dividing the resulting sum by the total number of trials.

Type of protest. Two mutually exclusive main coding categories served to classify children's spontaneous verbal interventions during the test phase: The central category of interest was rule protest, that is, explicit protest using normative vocabulary (e.g., "The [animal] must not go there!"), normative tattling (e.g., "He put it into the wrong one!"), or directives limiting action possibilities (e.g., saying, "Only into that one!" and pointing to Location A). The second category was group addressing, that is, phrases (including questions) and behaviors directed at the group (i.e., the proposer, Affirmers 1 or 2) referring to the protagonist's action without evaluating it normatively. Behaviors ranged from (non-normative) tattling or informing to asking for clarification or evaluation (e.g., "Look what he's doing!" and "The [Affirmer 1] should look!" and pointing toward protagonist while looking at the group and saying, "There, look!" or asking, "There?" and "The [animal] is now in [Location B]!"). For each trial, the final codes for the two categories were independent and dichotomous ( 1 or 0 ) based on whether children received the corresponding code at least once. A third coding category, implicit protest, was nonmutually exclusive with the two main ones such that it contained behaviors that either accompanied verbal interventions of one of the two main categories or occurred in isolation. Behaviors were informing or asking the protagonist (e.g., pointing toward Location A and saying, "There!" and unspecific disapproval like saying "No!" and "Why have you put it there?"), and any relevant pointing gestures toward Locations A, B, or the protagonist. For each trial, implicit protest was coded dichotomously. Overall, each child received a summed score (0-4) over the four trials for each of the three types of protest. Interrater reliability was very good (Cohen's $\kappa=0.95$, level of agreement; $\kappa=0.95$, imitation; $\kappa=0.92$, main protest categories; $\kappa=0.97$, implicit protest).

All above scores were computed based on four trials unless a child idiosyncratically opted for a location before the proposer made a suggestion to ensure experimental control and comparability across children (eight trials were thus excluded in total, one further trial due to equipment failure).

\section{Statistical Analysis}

For each response variable, we ran generalized linear models (GLMs). Information criterion statistics (Akaike's information criterion) were used to determine the best-fitting and most parsimonious model (Burnham \& Anderson, 2002; Schumacker \& Lomax, 2010). The three protest measures violated assumptions of standard linear models (i.e., normally distributed errors), and followed a Poisson distribution. Thus, for the protest measures, we used GLMs with Poisson error structure, and for imitation and level of agreement, we used Gaussian error structures. For the three protest measures, full models included the covariates imitation and level of agreement (both ztransformed), an offset term (log-transformed total valid number of trials per child) to adjust for the number of opportunities children had to perform protest (i.e., response variables were treated as rates), and the predictor condition. Likelihood ratio tests (Dobson, 2002) were used to test for the main effect of condition (by comparing the full model with a null model without the predictor condition). Based on the parameter 
estimates and standard errors of the full model, a planned linear contrast was performed for rule protest. For imitation and level of agreement, full models included the predictor condition only, and $F$ tests were used to test for the main effect of condition. Preliminary analyses found no effects of gender. Nagelkerke's $R^{2}$ (Nagelkerke, 1991) was computed to estimate effect sizes for main effects of condition, and 95\% confidence intervals were computed for parameter estimates.

\section{Results}

\section{Main Analyses}

Table 2 shows the mean scores (standard deviations) for each dependent measure including tests for the main effect of condition. The most unambiguous form of protest is rule protest as this category included normative language and action directives clearly referring to the violation of the agreed-upon norm. There was a significant main effect of condition (with medium effect size) on rule protest independent of the covariates imitation and level of agreement (see Table 2). The prediction for rule protest was that the agree condition would differ from the other three conditions (which would not differ from each other), because the agreed-upon norm was normatively binding for the protagonist in the agree condition only. The corresponding linear contrast (3, $-1,-1,-1)$ was significant, $F(1,58)=11.30$, $p=.001$ : Children performed significantly more rule protest in the agree condition $(M=0.94)$ than in the other three conditions (disagree, $M=0.13$; ignorant, $M=0.19$; quit, $M=0.19$ ). That is, children enforced the novel arbitrary norm when the protagonist had agreed on that norm, but not when she had disagreed, had been ignorant, or had quit the norm-setting process. Furthermore, children's level of agreement was a significant predictor of their rule protest, $b=0.39, S E=0.16, z=2.39, p=.02,95 \%$ CI $[0.06,0.71]$, such that higher levels of agreement were associated with more rule protest. Thus, children who did not perform any rule protest had a lower level of agreement $(M=1.69, S D=1.01)$ than children who performed rule protest at least once $(M=2.68, S D=1.68)$.

\section{Further Analyses}

For group addressing, there was a significant main effect of condition (with medium effect size) independent of the two covariates imitation and level of agreement (Table 2), indicating that children performed more group addressing in the agree $(M=0.63)$ and disagree $(M=0.50)$ conditions than in the ignorant $(M=0.06)$ and quit $(M=0.13)$ conditions. Children's group addressing differed significantly between the agree and the ignorant conditions, $b=2.16, S E=1.05, z=2.05, p=.04,95 \%$ CI $[0.50,5.07]$, and between the disagree and the ignorant conditions, $b=2.14, S E=1.07, z=2.01$, $p=.04,95 \%$ CI $[0.44,5.07]$, but no significant differences were found for agree versus quit conditions, $b=1.42, S E=0.79, z=1.79, p=.07,95 \%$ CI $[-0.04$, 3.32], or for disagree versus quit conditions, $b=1.40$, $S E=0.79, z=1.78, p=.08,95 \%$ CI $[-0.02,3.30]$. We also found a significant main effect of condition for implicit protest (with medium effect size; Table 2). Children in the agree condition performed the most implicit protest $(M=1.19)$ followed by the disagree $(M=0.63)$, ignorant $(M=0.31)$, and quit $(M=0.19)$ conditions. There were no significant effects of condition on children's imitation or level of agreement during the norm-setting phase (Table 2).

\section{Discussion}

Children in this experiment normatively enforced agreed-upon arbitrary norms only when

Table 2

Experiment 1: Mean Scores (Standard Deviation) per Condition and Main Effects of Condition for Each Dependent Measure

\begin{tabular}{llllll}
\hline & \multicolumn{4}{c}{ Condition } \\
\cline { 2 - 5 } Measure (range) & Agree & Disagree & Ignorant & Quit & Main effect of condition \\
\hline Rule protest (0-4) & $0.94(1.39)$ & $0.13(0.34)$ & $0.19(0.40)$ & $0.19(0.54)$ & $\chi^{2}(3)=12.39, p=.006, R^{2}=.22$ \\
Group addressing (0-4) & $0.63(1.15)$ & $0.50(0.89)$ & $0.06(0.25)$ & $0.13(0.5)$ & $\chi^{2}(3)=11.14, p=.01, R^{2}=.20$ \\
Implicit protest (0-4) & $1.19(1.38)$ & $0.63(0.89)$ & $0.31(0.48)$ & $0.19(0.54)$ & $\chi^{2}(3)=13.72, p=.003, R^{2}=.22$ \\
Imitation (-1 to 3) & $2.52(1.01)$ & $1.82(1.48)$ & $2.13(1.31)$ & $1.48(1.80)$ & $F(3,60)=1.51, p=.22, R^{2}=.07$ \\
Level of agreement $(-8$ to 8) & $2.16(1.45)$ & $1.74(0.84)$ & $2.12(1.23)$ & $1.61(1.38)$ & $F(3,60)=0.77, p=.52, R^{2}=.04$ \\
\hline
\end{tabular}

Note. Nagelkerke's $R^{2}$ scores indicate small ( $\left.\geq .02\right)$, medium $(\geq .13)$, or large ( $\left.\geq .26\right)$ effect sizes (Cohen, 1988). Models for the three protest measures controlled for children's imitation and level of agreement. 
the deviator had explicitly agreed to the suggested norm, but not when the deviator had disagreed with the norm, had been ignorant of the norm, or had quit the norm-setting process. This suggests that 3-year-olds understand that norms can be set by agreement. However, this experiment leaves open the question of how exactly children interpreted the disagree condition and thus also whether children need unanimity to see norms as established at all. Did they think that the norm did not apply to the dissenter (limited social scope) or that no norm got established (for anyone) whatsoever? Moreover, although children's lack of rule protest in the disagree condition suggests that they did not consider majority rule as a procedure for establishing norms, in this first experiment, there was only a majority of $80 \%$ (i.e., three puppets and the child). Thus, to assess more directly which of the three options (limited social scope, no norm establishment, majority rule) children favor in a situation of norm formation under dissent, we conducted a second experiment with an overwhelming majority of $90 \%$ preferring one course of action.

\section{Experiment 2}

In this experiment, we sought to assess how children deal with dissent during the norm-setting process given the three major options (limited social scope, no norm establishment, majority rule) discussed earlier. Three-year-olds witnessed a lone dissenter against a majority of $90 \%$ (i.e., eight puppets and the child) during the norm-setting process. Then, in the test phase, the deviating party was either a previous affirmer (affirmer condition) or the previous dissenter (dissenter condition) regarding the suggested norm. We increased the majority to $90 \%$ as compared to $80 \%$ in Experiment 1 to create a strong case against the hypothesis that, for young children, the majority does not determine the norm. If children fail to see any norm as established even in the presence of a majority of $90 \%$, this would provide strong support for the notion that 3-year-olds need unanimous agreement to understand norms as created at all. To rule out the possibility that children misidentify the protagonist as the dissenter in both conditions (e.g., the one who acts differently must be the one who said, "No!"), we included a memory test after each trial in which children were asked which puppet (affirmer vs. dissenter) had disagreed.
Method

\section{Participants}

Thirty-two 3-year-olds $(M=42$ months, range = 40-44 months; 16 girls, 16 boys) participated in the study from October to December 2014 and were recruited and tested as in Experiment 1. Eight additional children were tested, but excluded from the final sample due to experimenter error (4), uncooperativeness (3), or technical error (1).

\section{Design}

The number and order of tasks (warm-up session, norm-setting tasks) were identical to Experiment 1 . Children were randomly assigned to one of the two between-participants conditions: affirmer or dissenter.

\section{Materials}

In addition to the objects used in Experiment 1, there were five additional puppets (a cow, a lion, a fox, a hedgehog, and a snow leopard) and a semitransparent barrier.

\section{Procedure}

The general procedure was identical to Experiment 1 with the following exceptions. There were two protagonist puppets (a cow operated by the left hand of E1 who sat to the child's left, and a rabbit operated by the right hand of E2 who sat to the child's right as in Experiment 1) that served as the affirmer and dissenter (puppet's identity, cow vs. rabbit, counterbalanced across children). Thus, during the warm-up session, either the affirmer (affirmer condition) or the dissenter (dissenter condition) made a mistake in the instrumental task. The proposer (polar bear, controlled by E2, left hand) and Affirmer 1 (camel, controlled by E1, right hand) were the two puppets located right next to the child (in Experiment 1, Affirmer 1 was on E1's left hand; see Figure 1). Thus, the two protagonist puppets (affirmer, dissenter) were located as the protagonist in Experiment 1 (but on both the left- and right-hand sides). Five additional affirming puppets (Affirmers 2-6: mouse, lion, fox, hedgehog, snow leopard) were positioned standing behind Locations A and B (from the child's viewpoint) from the middle to the left or right (depending on the affirmer's location) and were operated by the experimenter who controlled the affirmer. 
Table 3 provides an overview of the two conditions and the phases of the norm-setting task including the dependent measures recorded. As in Experiment 1, the proposer suggested playing a game, but before the protagonist phase (i.e., the affirmer's and dissenter's speech acts, order counterbalanced across children), Affirmers 2-6 assented to the suggested norm (see Table 3). During the test phase, to make sure that children experienced the same situation as in Experiment 1 (i.e., all parties are present and addressable, but not watching the protagonist's act during test), the proposer put a semitransparent barrier in front of Affirmers 2-6 (so that their contours were still visible), while Affirmer 1 announced that the protagonist has got the objects (see Table 3). Following each trial, E2 asked participants a memory control question about which puppet (affirmer vs. dissenter) disagreed with the suggested norm (i.e., "Show me, who of the two said No earlier?"). Before this question was asked, Affirmer 1 removed the stuffed animal from the respective location in order not to bias children toward one location and thus potentially toward the puppet who was acting.

\section{Coding and Dependent Measures}

Coding was the same as in Experiment 1 (for additional measures, see Results). Interrater reliability was very good (Cohen's $\kappa=0.96$, level of agreement; $\kappa=1$, imitation; $\kappa=1$, main protest categories; $\kappa=0.85$, implicit protest; $\kappa=1$, memory question). One trial was excluded due to uncooperativeness.

\section{Statistical Analysis}

Analyses were carried out as in Experiment 1. For the measures rule protest and group addressing, we used nonparametric statistics (exact MannWhitney $U$ tests) instead of GLMs, because there were means and variances of zero in one condition (i.e., complete separation) and little variation in the other condition, resulting in unstable and poorly fitted models (Rao \& Rao, 2014). Thus, the nonparametric analyses on rule protest and group addressing did not control for children's imitation and level of agreement. For nonparametric tests, we computed the generic effect size $r_{\text {equivalent }}$ (Rosenthal \& Rubin, 2003) and also report the squared

Table 3

Experiment 2: Phases and Measures in the Norm-Setting Task for Each Condition

\begin{tabular}{|c|c|c|}
\hline \multirow[b]{2}{*}{ Phase } & Condition & \multirow[b]{2}{*}{ Dependent measure } \\
\hline & Dissenter & \\
\hline Introductory & $\begin{array}{l}\text { Affirmer } 1 \text { fetches objects out of a bag. Proposer names the objects (e.g., "Boxes, and a } \\
\text { ladybug.") and asks "Well, do we want to play a game?"; Affirmer } 1 \text { "Oh yes!" }\end{array}$ & \\
\hline Norm setting & $\begin{array}{l}\text { 1. Proposer "Ah yes, the [animal] may do X at this [Location A], but it may not do X at } \\
\text { that [Location B], ok?" (Observation 1) } \\
\text { 2. Affirmer } 1 \text { "Ah yes, the [animal] may do X at this [Location A], but not at that [Location } \\
\text { B], ok?", looking at the child (Observation 2) } \\
\text { 3. Proposer puts [animal] next to suggested location, agrees ("Ok, then the [animal] may } \\
\text { only use this [Location A]"); Affirmers } 1 \text { to } 6 \text { agree (Observation 3) }\end{array}$ & $\begin{array}{l}\text { Level of agreement } \\
\text { (Observations 1-3) }\end{array}$ \\
\hline Protagonist & $\begin{array}{l}\text { 1. Affirmer "The [animal] may only use this [Location A], and not that [Location B]! Me, } \\
\text { the [cow/rabbit], I am for this [Location A]." } \\
\text { 2. Dissenter "No, we play: the [animal] may not use this [Location A], the [animal] may } \\
\text { only use that [Location B]!" (order of affirmer/dissenter counterbalanced) }\end{array}$ & \\
\hline Action & $\begin{array}{l}\text { 1. Proposer "Well, we play that the [animal] may only use this [Location A], but not that } \\
\text { [Location B]" (Observation 4), performs action X at Location A } \\
\text { 2. Child may play } \\
\text { 3. Affirmer } 1 \text { performs action X at Location A, repeating the agreed-upon norm }\end{array}$ & $\begin{array}{l}\text { Level of agreement } \\
\text { (Observation 4), } \\
\text { Imitation }\end{array}$ \\
\hline Test & $\begin{array}{l}\text { 1. Affirmer } 1 \text { gives objects to protagonist and says to the child "Now the [protagonist] has } \\
\text { got this, have a look!" Concurrently, the proposer puts the barrier in front of Affirmers } 2 \\
\text { to } 6 \text {. Proposer, Affirmer } 1 \text { and nonacting protagonist turn toward respective experimenter. }\end{array}$ & \\
\hline & $\begin{array}{l}\text { 2. Affirmer performs action } X \text { at alternative } \\
\text { (forbidden) Location } B\end{array}$ & Protest \\
\hline
\end{tabular}

Note. The status of location (permitted, forbidden) was counterbalanced across children. $\mathrm{X}=$ action performed (see Appendix S1) with stuffed animal at Location A/B. 
value to allow for comparability with Nagelkerke's $R^{2}$. Preliminary analyses found no effects of gender.

\section{Results}

\section{Main Analyses}

Table 4 presents the mean scores (standard deviations) for each dependent measure including tests for the effect of condition. Children's behavior did not differ significantly between conditions for any of the dependent measures. Even when collapsing all three types of protest into an overall protest measure (i.e., a summed score, $0-4$, based on whether children produced rule protest, group addressing, or implicit protest), there was no significant difference between the affirmer $(M=0.63)$ and dissenter $(M=0.19)$ conditions (see Table 4). As in Experiment 1 , children's level of agreement was correlated with their protest behavior (overall protest, $b=0.50$, $S E=0.21, z=2.39, p=.02,95 \%$ CI [0.08, 0.92]; implicit protest, $b=0.66, S E=0.25, z=2.63$, $p=.009,95 \%$ CI $[0.17,1.18])$, such that higher levels of agreement were associated with more protest.

\section{Further Analyses}

There were no significant effects of condition on children's imitation or level of agreement during the norm-setting phase, but slightly larger means for both measures in the affirmer condition (Table 4). This pattern, however, was not present on the first trial before children witnessed the different protagonists (affirmer vs. dissenter) in the test phase, neither for imitation (affirmer condition, $M=1.94, S D=1.65$; dissenter condition, $M=1.63, S D=1.86)$ or for level of agreement (affirmer condition, $M=2.13, S D=2.0$; dissenter condition, $M=2.19, S D=1.22)$. With respect to the memory control question, children predominantly correctly identified the dissenter (affirmer condition, $79 \%$ of trials; dissenter condition, $68 \%$ of trials). There was no difference between conditions, $t(26)=0.89, p=.39$, and a one-sample $t$ test indicated that children (collapsed across condition) answered the memory question correctly at levels significantly above chance (.50), $t(26)=3.82$, $p<.001$. The results remained the same if trials in which children misidentified the dissenter were excluded.

\section{Discussion}

In this experiment, children performed little rule protest and there was no difference between conditions, suggesting that children did not understand the protagonist's deviating acts as norm violations, irrespective of whether they witnessed a previous affirmer or a previous dissenter. Children's good performance in the memory test speaks against the possibility that the lack of protest was due to children misidentifying the affirmer as the dissenter. It is noteworthy that even in the presence of a majority of $90 \%$, children did not see any norms as established at all.

\section{General Discussion}

The present study asked whether young children understand the role of agreement in establishing mutually binding social norms and under which conditions they infer that norms have been created. We found that children normatively expected rule conformity only when a deviator had entered into the agreement. They did not demand conformity

Table 4

Experiment 2: Mean Scores (Standard Deviation) per Condition and Effects of Condition for Each Dependent Measure

\begin{tabular}{|c|c|c|c|}
\hline \multirow[b]{2}{*}{ Measure (range) } & \multicolumn{2}{|c|}{ Condition } & \multirow[b]{2}{*}{ Effect of condition } \\
\hline & Affirmer & Dissenter & \\
\hline Rule protest $(0-4)$ & 0.44 (1.09) & $0(0)$ & $U=152, p=.23, r_{\text {equivalent }}=.22\left(R^{2}=.05\right)$ \\
\hline Group addressing $(0-4)$ & $0.13(0.34)$ & $0(0)$ & $U=144, p=.48, r_{\text {equivalent }}=.13\left(R^{2}=.02\right)$ \\
\hline Implicit protest $(0-4)$ & $0.44(0.89)$ & $0.19(0.54)$ & $\chi^{2}(1)=0.06, p=.81, R^{2}=.003$ \\
\hline Overall protest $(0-4)$ & $0.63(1.09)$ & $0.19(0.54)$ & $\chi^{2}(1)=1.14, p=.29, R^{2}=.04$ \\
\hline Imitation $(-1$ to 3$)$ & $2.47(0.91)$ & $1.81(1.22)$ & $F(1,30)=2.97, p=.10, R^{2}=.09$ \\
\hline Level of agreement ( -8 to 8 ) & $2.72(1.64)$ & $1.95(0.85)$ & $F(1,30)=2.74, p=.11, R^{2}=.09$ \\
\hline
\end{tabular}

Note. The measures rule protest and group addressing were analyzed with exact Mann-Whitney $U$ tests due to low variation in the response (see Statistical Analysis). Models for implicit protest and overall protest controlled for children's imitation and level of agreement. 
when a deviating individual had not entered into the agreement, had been ignorant of, or had disagreed with, the group's norm. That is, children acted as if they had a normative standing to demand conformity (Gilbert, 2008) only when the informal contract was "signed" by the deviating party. Interestingly, however, when there was dissent during the norm-formation process, children failed to see any norms being established whatsoever, either for a previous dissenter or for a previous affirmer - even if a majority of $90 \%$ explicitly endorsed one course of action. Hence, children did not view dissent as simply limiting the social scope to those who had agreed on the norm, but as vitiating the establishment of a norm altogether. This suggests that while young children understand that an agreement has normative consequences, they make this inference only under conditions of unanimous agreement among all present parties.

Children did not enforce agreed-upon norms on individuals who had quit the norm-setting process or had been ignorant of the norm. This suggests that children do not indiscriminately enforce agreed-upon norms on anyone in the absence of dissent; they take into account whether the deviator was part of the norm-setting process, and thus the deviator's knowledge state. In fact, even young children show some competence in attributing ignorance to others (Hogrefe, Wimmer, \& Perner, 1986), and they evaluate intentional rule violations as more reprehensible than accidental ones (Núñez \& Harris, 1998). This might be one reason why children refrained from criticizing an ignorant party in the present study. Overall, our findings are consistent not only with recent evidence of 3-year-olds' context- and group-relative understanding of social norms (e.g., Rakoczy, Brosche, et al., 2009; Schmidt et al., 2012), but they also go beyond prior studies, because children enforced norms that were neither preexisting nor set by adults; rather, these norms were jointly set by agreement.

Importantly, children's understanding of the binding force of jointly agreed-upon norms was independent of their spontaneous level of agreement (with suggested norms) and their imitation (i.e., their own preferred course of action), suggesting that their consideration of unanimously agreedupon norms is independent of their potential preference for these norms. Nonetheless, children's level of agreement was a significant predictor of their protest, which suggests that one underlying motivation for enforcing norms might be conviction in, or commitment to, those norms (Münch, 1987; Rossano, 2012; Schmidt \& Tomasello, 2012). And this positive relation between level of agreement and protest also means that little endorsement or even disagreement with suggested norms (i.e., being a dissenter oneself, as it were) is related to nonenforcement of norms, and perhaps even endorsement of deviance (cf. Cooley \& Killen, 2015).

The current findings suggest that while young children understand that norms can be set by agreement and are binding for those who agree (e.g., not for ignorant parties), their understanding of mechanisms of norm creation is confined to situations of unanimous agreement. That is, similar to young children's focus on unanimity in activities based on individual intentionality, such as their social learning and epistemic trust (e.g., Morgan et al., 2015; Pasquini et al., 2007), we found that young children focus on unanimity in the creation of arbitrary game norms that are based on shared intentionality as simple examples of human institutions (Rakoczy \& Schmidt, 2013; Schmidt \& Tomasello, 2012; Searle, 1995). An interesting question for future research is whether young children's focus on unanimity reflects an egalitarian stance that all parties are equivalent and entitled to have a voice-for instance, when there is no hierarchical adult-child relationship (Piaget, 1932) or institutional context (Helwig \& Kim, 1999) — or whether it reflects other cognitive mechanisms, such as difficulty in dealing with conflicting perspectives regarding the same state of affairs or executive limitations (Perner, Zauner, \& Sprung, 2005; Rakoczy, 2010).

Even though children did not see any norms being established when there was dissent, in Experiment 1 they tended to inform the group more in the disagree condition than in the ignorant and quit conditions, and there was hardly any protest on all measures in the quit condition. This could be explained by the fact that in the disagree condition, the protagonist was still part of the norm-setting process and remained "in-group," whereas in the other two conditions, the protagonist was not part of or left the norm-setting process. One possibility is that children respected the quitting party's autonomy to leave the norm-setting process, given that young children understand something about individual rights and entitlements (Neary \& Friedman, 2014; Schmidt, Rakoczy, \& Tomasello, 2013) and the concept of personal choice, for instance, when decisions are about preferences and do not inflict any harm (Nucci, 2014; Nucci \& Weber, 1995). In the disagree condition, however, children might have attempted to have the group evaluate the deviant act to reduce uncertainty and ambiguity (about what "we" desire), since the dissenter represented a considerable minority (one of 
five parties). In Experiment 2, however, children produced hardly any group addressing, which could be due to the fact that the dissenter was in a small minority (1 of 10 parties) and spoke after the vast majority of individuals had already assented to one option, therefore leaving little uncertainty about what the group wants.

Overall, protest rates were rather low: about 25\% of trials in the agree condition (Experiment 1). However, this rate refers to children's (normative) rule protest and is comparable to rates of normative protest in other studies (Rakoczy, Brosche, et al., 2009; Rakoczy, Warneken, \& Tomasello, 2009; Schmidt, Rakoczy, \& Tomasello, 2011; Schmidt et al., 2012; Wyman et al., 2009). Nonetheless, one reason for these results could be the evident arbitrariness of the norms in our study: The question was not how to perform an act; it was always the very same act $X$ (i.e., the protagonist performed the correct act $X$, e.g., letting the ladybug sleep). The question was merely where to perform act $X$, at Location $\mathrm{A}$ or at Location B. This is different from performing distinct actions (e.g., $\mathrm{X}$ vs. $\mathrm{Y}$ ) on artifacts that look as if they were built for a certain purpose and thus come with some "inherent" normativity (Rakoczy et al., 2008; Schmidt et al., 2011). And it is also different from pretense, which is again about someone's actions per se, for instance, that an actor should treat a block as a banana $(\mathrm{X})$ but not as a telephone (Y) in a given context (Rakoczy, 2008). Hence, the arbitrariness of the game rules established in this study might have biased some children toward a generous reading of deviant acts (in contrast, e.g., to moral violations, which are typically considered more severe; Turiel, 1983, 2006), but it might also have allowed children to appreciate that there is no preexisting, objective rule everyone will or should adhere to. In contrast, when confronting young children with preexisting, adultset social norms, they take an objectivist stance and expect even ignorant actors to adhere to these norms as to laws of physics, to be aware of them, and to be blamed for violating them (Kalish, 1998; Kalish \& Cornelius, 2007; Kalish, Weissman, \& Bernstein, 2000).

In sum, our findings suggest that young children understand that arbitrary norms with binding force can be set by agreement. Children take into account whether a deviating party had been part of the agreement and thus do not enforce novel norms when someone was ignorant of the agreement or had left the norm-setting process. However, young children's initial understanding of mechanisms of norm creation is limited and rigid: They seem to take unanimity as key to norm establishment and any dissent, even by a small minority, prevents children from seeing a norm as coming into effect at all. Nonetheless, our findings suggest that by age 3 , children take an active role in their norm acquisition and have some basic understanding of the social nature of normative phenomena and the normative consequences of norm creation. The norms in this study were highly arbitrary and thus a paradigmatic example of social norms whose adherence cannot be solely explained by instrumental reasons or because they are self-enforcing. Rather, adherence to such norms may be based on "social" reasons whose binding force comes from how "we" agree that "we" should behave (Rossano, 2012; Schmidt \& Tomasello, 2012; Tomasello, 2009).

\section{References}

Abrams, D., Palmer, S. B., Rutland, A., Cameron, L., \& Van de Vyver, J. (2014). Evaluations of and reasoning about normative and deviant ingroup and outgroup members: Development of the black sheep effect. Developmental Psychology, 50, 258-270. doi:10.1037/a0032461

Abrams, D., Rutland, A., \& Cameron, L. (2003). The development of subjective group dynamics: Children's judgments of normative and deviant in-group and outgroup individuals. Child Development, 74, 1840-1856. doi:10.1046/j.1467-8624.2003.00641.x

Abrams, D., Rutland, A., Ferrell, J. M., \& Pelletier, J. (2008). Children's judgments of disloyal and immoral peer behavior: Subjective group dynamics in minimal intergroup contexts. Child Development, 79, 444-461. doi:10.1111/j.1467-8624.2007.01135.x

Boehm, C. (1999). Hierarchy in the forest: The evolution of egalitarian behavior. Cambridge, MA: Harvard University Press.

Burnham, K. P., \& Anderson, D. R. (2002). Model selection and multi-model inference: A practical information-theoretic approach (2nd ed.). New York, NY: Springer.

Carassa, A., \& Colombetti, M. (2014). Interpersonal responsibilities and communicative intentions. Phenomenology and the Cognitive Sciences, 13, 145-159. doi:10.1007/s11097-013-9325-z

Cohen, J. (1988). Statistical power analysis for the behavioral sciences (2nd ed.). Hillsdale, NJ: Erlbaum.

Cooley, S., \& Killen, M. (2015). Children's evaluations of resource allocation in the context of group norms. Developmental Psychology, 51, 554-563. doi:10.1037/ a0038796

Corriveau, K. H., Fusaro, M., \& Harris, P. L. (2009). Going with the flow: Preschoolers prefer nondissenters as informants. Psychological Science, 20, 372-377. doi:10.1111/j.1467-9280.2009.02291.x

Corriveau, K. H., \& Harris, P. L. (2010). Preschoolers (sometimes) defer to the majority in making simple 
perceptual judgments. Developmental Psychology, 46, 437-445. doi:10.1037/a0017553

Cummins, D. D. (2013). Deontic reasoning as a target of selection: Reply to Astington and Dack. Journal of Experimental Child Psychology, 116, 970-974. doi:10.1016/j.jecp.2013.03.005

Darwall, S. (2006). The second-person standpoint: Morality, respect, and accountability. Cambridge, MA: Harvard University Press.

Dobson, A. J. (2002). An introduction to generalized linear models (2nd ed.). Boca Raton, FL: Chapman \& Hall/CRC.

Gilbert, M. (2008). Social convention revisited. Topoi, 27, 5-16. doi:10.1007/s11245-008-9032-5

Göckeritz, S., Schmidt, M. F. H., \& Tomasello, M. (2014). Young children's creation and transmission of social norms. Cognitive Development, 30, 81-95. doi:10.1016/ j.cogdev.2014.01.003

Gray, P. (2009). Play as a foundation for hunter-gatherer social existence. American Journal of Play, 1, 476-522.

Hart, H. L. A. (1961). The concept of law. Oxford, UK: Oxford University Press.

Haun, D. B. M., \& Tomasello, M. (2011). Conformity to peer pressure in preschool children. Child Development, 82, 1759-1767. doi:10.1111/j.1467-8624.2011.01666.x

Helwig, C. C. (1998). Children's conceptions of fair government and freedom of speech. Child Development, 69, 518-531. doi:10.1111/j.1467-8624.1998.tb06205.x

Helwig, C. C., \& Kim, S. (1999). Children's evaluations of decision-making procedures in peer, family, and school contexts. Child Development, 70, 502-512. doi:10.1111/ 1467-8624.00036

Hitti, A., Mulvey, K. L., Rutland, A., Abrams, D., \& Killen, M. (2014). When is it okay to exclude a member of the ingroup? Children's and adolescents' social reasoning. Social Development, 23, 451-469. doi:10.1111/sode. 12047

Hogrefe, G.-J., Wimmer, H., \& Perner, J. (1986). Ignorance versus false belief: A developmental lag in attribution of epistemic states. Child Development, 57, 567-582. doi: $10.2307 / 1130337$

Kalish, C. W. (1998). Reasons and causes: Children's understanding of conformity to social rules and physical laws. Child Development, 69, 706-720. doi:10.2307/ 1132199

Kalish, C. W. (2005). Becoming status conscious: Children's appreciation of social reality. Philosophical Explorations, 8, 245-263. doi:10.1080/07418820500219359

Kalish, C. W., \& Cornelius, R. (2007). What is to be done? Children's ascriptions of conventional obligations. Child Development, 78, 859-878. doi:10.1111/j.1467-8624.2007. 01037.x

Kalish, C. W., Weissman, M., \& Bernstein, D. (2000). Taking decisions seriously: Young children's understanding of conventional truth. Child Development, 71, 1289-1308. doi:10.1111/1467-8624.00229

Kelsen, H. (1960). Reine Rechtslehre. Mit einem Anhang: Das Problem der Gerechtigkeit ;[Pure theory of law] (2nd ed.). Vienna, Austria: F. Deuticke.
Kenward, B. (2012). Over-imitating preschoolers believe unnecessary actions are normative and enforce their performance by a third party. Journal of Experimental Child Psychology, 112, 195-207. doi:10.1016/j.jecp. 2012.02.006

Killen, M., \& Rutland, A. (2011). Children and social exclusion: Morality, prejudice, and group identity. New York, NY: Wiley-Blackwell.

Legare, C. H., \& Souza, A. L. (2012). Evaluating ritual efficacy: Evidence from the supernatural. Cognition, 124, 1-15. doi:10.1016/j.cognition.2012.03.004

Lewis, D. K. (1969). Convention. A philosophical study. Cambridge, MA: Harvard University Press.

McAdams, R. H. (1997). The origin, development, and regulation of norms. Michigan Law Review, 96, 338-433.

Morgan, T. J. H., Laland, K. N., \& Harris, P. L. (2015). The development of adaptive conformity in young children: Effects of uncertainty and consensus. Developmental Science, 18, 511-524. doi:10.1111/desc.12231

Mulvey, K. L., Hitti, A., Rutland, A., Abrams, D., \& Killen, M. (2014a). Context differences in children's ingroup preferences. Developmental Psychology, 50, 1507-1519. doi:10.1037/a0035593

Mulvey, K. L., Hitti, A., Rutland, A., Abrams, D., \& Killen, M. (2014b). When do children dislike ingroup members? Resource allocation from individual and group perspectives. Journal of Social Issues, 70, 29-46. doi:10.1111/josi.12045

Münch, R. (1987). Parsonian theory today: In search of a new synthesis. In A. Giddens \& J. H. Turner (Eds.), Social theory today (pp. 116-155). Stanford, CA: Stanford University Press.

Nagelkerke, N. J. D. (1991). A note on a general definition of the coefficient of determination. Biometrika, 78, 691692. doi:10.1093/biomet/78.3.691

Neary, K. R., \& Friedman, O. (2014). Young children give priority to ownership when judging who should use an object. Child Development, 85, 326-337. doi:10.1111/ cdev.12120

Nesdale, D., Lawson, M. J., Durkin, K., \& Duffy, A. (2010). Effects of information about group members on young children's attitudes towards the in-group and out-group. British Journal of Developmental Psychology, 28,467-482. doi:10.1348/026151009X433321

Nesdale, D., Maass, A., Kiesner, J., Durkin, K., Griffiths, J., \& James, B. (2009). Effects of peer group rejection and a new group's norms on children's intergroup attitudes. British Journal of Developmental Psychology, 27, 799-814. doi:10.1348/026151008X381690

Nielsen, M., Kapitány, R., \& Elkins, R. (2015). The perpetuation of ritualistic actions as revealed by young children's transmission of normative behavior. Evolution and Human Behavior, 36, 191-198. doi:10.1016/j.evolhum behav.2014.11.002

Nobes, G. (1999). Children's understanding of rules they invent themselves. Journal of Moral Education, 28, 215232. doi:10.1080/030572499103232 
Nucci, L. P. (2014). The personal and the moral. In M. Killen \& J. G. Smetana (Eds.), Handbook of moral development (2nd ed., pp. 538-558). New York, NY: Psychology Press.

Nucci, L. P., \& Weber, E. K. (1995). Social interactions in the home and the development of young children's conceptions of the personal. Child Development, 66, 1438-1452. doi:10.2307/1131656

Núñez, M., \& Harris, P. L. (1998). Psychological and deontic concepts: Separate domains or intimate connection? Mind $\mathcal{E}$ Language, 13, 153-170. doi:10.1111/14680017.00071

Pasquini, E. S., Corriveau, K. H., Koenig, M., \& Harris, P. L. (2007). Preschoolers monitor the relative accuracy of informants. Developmental Psychology, 43, 1216-1226. doi:10.1037/0012-1649.43.5.1216

Perner, J., Zauner, P., \& Sprung, M. (2005). What does "that" have to do with points of view? Conflicting desires and "want" in German. In J. W. Astington \& J. A. Baird (Eds.), Why language matters for theory of mind (pp. 220-244). New York, NY: Oxford University Press.

Piaget, J. (1932). The moral judgment of the child. London, UK: Routledge Kegan Paul.

Prothro, J. W., \& Grigg, C. M. (1960). Fundamental principles of democracy: Bases of agreement and disagreement. Journal of Politics, 22, 276-294.

Rakoczy, H. (2008). Pretence as individual and collective intentionality. Mind $\mathcal{E}$ Language, 23, 499-517. doi:10.1111/j.1468-0017.2008.00357.x

Rakoczy, H. (2010). Executive function and the development of belief-desire psychology. Developmental Science, 13, 648-661. doi:10.1111/j.1467-7687.2009.00922.x

Rakoczy, H., Brosche, N., Warneken, F., \& Tomasello, M. (2009). Young children's understanding of the context relativity of normative rules in conventional games. British Journal of Developmental Psychology, 27, 445-456. doi:10.1348/026151008X337752

Rakoczy, H., Hamann, K., Warneken, F., \& Tomasello, M. (2010). Bigger knows better: Young children selectively learn rule games from adults rather than from peers. British Journal of Developmental Psychology, 28, 785-798. doi:10.1348/026151009X479178

Rakoczy, H., \& Schmidt, M. F. H. (2013). The early ontogeny of social norms. Child Development Perspectives, 7, 17-21. doi:10.1111/cdep.12010

Rakoczy, H., Warneken, F., \& Tomasello, M. (2008). The sources of normativity: Young children's awareness of the normative structure of games. Developmental Psychology, 44, 875-881. doi:10.1037/0012-1649.44.3.875

Rakoczy, H., Warneken, F., \& Tomasello, M. (2009). Young children's selective learning of rule games from reliable and unreliable models. Cognitive Development, 24, 61-69. doi:10.1016/j.cogdev.2008.07.004

Rao, M. B., \& Rao, C. R. (Eds.). (2014). Handbook of statistics: Computational statistics with $R$ (Vol. 32). Amsterdam, Netherlands: Elsevir.

Rosenthal, R., \& Rubin, D. (2003). r requivalent: A simple effect size indicator. Psychological Methods, 8, 492-496. doi:10.1037/1082-989X.8.4.492
Rossano, M. J. (2012). The essential role of ritual in the transmission and reinforcement of social norms. Psychological Bulletin, 138, 529-549. doi:10.1037/a0027038

Rossano, F., Rakoczy, H., \& Tomasello, M. (2011). Young children's understanding of violations of property rights. Cognition, 121, 219-227. doi:10.1016/j.cognition.2011.06.007

Rutland, A., Killen, M., \& Abrams, D. (2010). A new social-cognitive developmental perspective on prejudice: The interplay between morality and group identity. Perspectives on Psychological Science, 5, 279-291. doi:10.1177/1745691610369468

Schmidt, M. F. H., \& Rakoczy, H. (in press). On the uniqueness of human normative attitudes. In K. Bayertz \& N. Roughley (Eds.), The normative animal? On the anthropological significance of social, moral and linguistic norms. Oxford, NY: Oxford University Press.

Schmidt, M. F. H., Rakoczy, H., \& Tomasello, M. (2011). Young children attribute normativity to novel actions without pedagogy or normative language. Developmental Science, 14, 530-539. doi:10.1111/j.1467-7687.2010.01 000.x

Schmidt, M. F. H., Rakoczy, H., \& Tomasello, M. (2012). Young children enforce social norms selectively depending on the violator's group affiliation. Cognition, 124, 325-333. doi:10.1016/j.cognition.2012.06.004

Schmidt, M. F. H., Rakoczy, H., \& Tomasello, M. (2013). Young children understand and defend the entitlements of others. Journal of Experimental Child Psychology, 116, 930-944. doi:10.1016/j.jecp.2013.06.013

Schmidt, M. F. H., \& Tomasello, M. (2012). Young children enforce social norms. Current Directions in Psychological Science, 21, 232-236. doi:10.1177/0963721412448659

Schumacker, R. E., \& Lomax, R. G. (2010). A beginner's guide to structural equation modeling (3rd ed.). New York, NY: Routledge, Taylor \& Francis.

Searle, J. R. (1995). The construction of social reality. New York, NY: Free Press.

Seston Schillaci, R., \& Kelemen, D. (2013). Children's conformity when acquiring novel conventions: The case of artifacts. Journal of Cognition and Development, 15, 569583. doi:10.1080/15248372.2013.784973

Smetana, J. G. (2006). Social-cognitive domain theory. Consistencies and variations in children's moral and social judgments. In M. Killen \& J. G. Smetana (Eds.), Handbook of moral development (pp. 119-154). Mahwah, NJ: Erlbaum.

Tomasello, M. (2009). Why we cooperate. Cambridge, MA: MIT Press.

Tuomela, R. (2007). The philosophy of sociality. New York, NY: Oxford University Press.

Turiel, E. (1983). The development of social knowledge: Morality and convention. Cambridge, UK: Cambridge University Press.

Turiel, E. (2006). The development of morality. In W. Damon, R. M. Lerner, \& N. Eisenberg (Eds.), Handbook of child psychology: Vol. 3. Social, emotional, and personality development (6th ed., pp. 789-857). Hoboken, NJ: Wiley. 
Turner, C. R., Nielsen, M., \& Collier-Baker, E. (2014). Groups' actions trump injunctive reaction in an incidental observation by young children. PLoS ONE, 9, e107375. doi:10.1371/journal.pone.0114789

Wyman, E., Rakoczy, H., \& Tomasello, M. (2009). Normativity and context in young children's pretend play. Cognitive Development, 24, 146-155. doi:10.1016/j.cogdev.2009.01.003

\section{Supporting Information}

Additional supporting information may be found in the online version of this article at the publisher's website:

Appendix S1. Materials and Actions Used in the Norm-Setting Tasks 